\section{KICk-starting European enterprise}

\section{By Lev Osherovich, Senior Writer}

After cutting its teeth with investments in energy and communications in 2010, the European Institute of Innovation and Technology is making long-term plans for a move into the biopharmaceutical space. To do so, the institute has tapped long-standing board member Alexander von Gabain to become its chairman when founding chairman Martin Schuurmans steps down in September.

The European Institute of Innovation and Technology (EIT) was launched in 2008 as an autonomous grant-giving agency endowed with $€ 308$ million (\$430 million) from the European Commission (EC). EIT's mission is to encourage entrepreneurship at European academic centers by funding academic-industry joint ventures called Knowledge and Innovation Communities (KICs).

KICs are international consortia consisting of academic and industry teams. To form a KIC, teams from "four or five cities come together and facilitate collaboration with companies while encouraging academic contacts between universities," said von Gabain, who is

"If you combine the four or
five best players in a field,
you get critical mass."
-Alexander von Gabain,
European Institute of
Innovation and Technology

milestones, they become eligible for further payments, up to about $€ 100$ million (\$140 million) per KIC through 2015.

"We want to run this like a high-impact investment fund. The money we give as seed money is bound by certain milestones" including additional fundraising, said von Gabain. The value proposition to universities and companies is that "we give money if you write a business plan, hire a CEO and raise more money."

In EIT's first round of KIC financing in 2009, the institute received 20 proposals in 3 areas - climate change, sustainable energy and communication technologies. Ultimately the institute funded a single consortium for each topic. Each KIC consists of about 12 companies and universities throughout the EU.

Von Gabain said the 3 KICs have received about $€ 40$ million (\$56 million) in total from EIT so far, and the sustainable energy KIC is ready to launch spinout companies that have raised venture capital, triggering an undisclosed milestone payment from EIT.

EIT now has $€ 290$ million ( $\$ 405$ million) under management, "and the EC is inclined to give us another $€ 1.5-€ 2.5$ billion [ $\$ 2.1-\$ 3.5$ billion]" to fund 7-9 more KICs in a next round of financing, which should take place in 2012 or 2013, von Gabain said.

The next call for KIC proposals in 2012 will focus on biosciences. EIT is considering "pretty wide topics, like problems of aging populations or antibiotic resistance," said von Gabain.

Although the specific topics are undecided, von Gabain said he hopes to encourage development of ideas that have commercial potential but "don't fit into the classical pharma scheme" of blockbuster drugs.

One potential topic of interest is narrowspectrum antibiotics.

"Current treatment with antibiotics is a cofounder and chairman of the scientific advisory board of the Austrian vaccine maker Intercell AG and professor of microbiology at the Max F. Perutz Laboratories.

As an example, von Gabain cited the renewable energy KIC funded in 2009, which consists of academic centers and companies in four European cities-Karlsruhe, Germany; Grenoble, France, EindhovenLeuven, the Netherlands; and Barcelona, Spain-plus others in Sweden and Poland. Participating researchers work at designated sites in each city, and all sites are coordinated by a single management team, including a CEO who is hired by each consortium to run the commercial aspects of the project.

"We want to achieve critical mass for a specific topic," he added. "If you combine the four or five best players in a field, you get critical mass."

According to von Gabain, the company-like structure of each KIC and a requirement for additional funding from the private sector sets the program apart from conventional research funding schemes such as the EC's Framework Program.

KICs work like virtual companies led by a CEO. EIT can provide no more than $25 \%$ of the money for each KIC, with a typical initial outlay of $€ 10$ million ( $\$ 14$ million). When KICs hit mutually agreed upon horror-with broad-spectrum antibiotics you kill everything" including normal microfauna, the absence of which has been implicated in obesity and metabolic disease, said von Gabain.

"There is room for new applications that move away from the classical pharma paradigm of bombardment with antibiotics," he noted.

Von Gabain argued that pharma's hunger for universally applicable blockbuster drugs has stymied development of more specialized products aimed at select patient populations.

"Pharmas are trapped in the dilemma of following up on fading blockbusters," he said. "Little startups play that game by thinking that they too can make blockbusters, but there are other ways to earn money in health care."

Von Gabain noted that some of the approaches EIT hopes to fund "may go out of the classical biotech space," including nutritional science.

Osherovich, L. SciBX 4(10); doi:10.1038/scibx.2011.273

Published online March 10, 2011

COMPANIES AND INSTITUTIONS MENTIONED

European Institute of Innovation and Technology, Budapest, Hungary Intercell AG (VSE:ICLL; OTCQX:INRLY), Vienna, Austria

Max F. Perutz Laboratories, Vienna, Austria 